\title{
BLENDED LEANING AS AN OPTIMAL AND EFFECTIVE FORM OF MODERN EDUCATION
}

\section{СМЕШАННОЕ ОБУЧЕНИЕ \\ КАК ОПТИМАЛЬНАЯ И ЭФФЕКТИВНАЯ ФОРМА СОВРЕМЕННОГО ОБРАЗОВАНИЯ}

\section{Olena Fedotova ${ }^{1}$ \\ Iryna Tomaz ${ }^{2}$}

DOI: https://doi.org/10.30525/978-9934-26-021-6-7

\begin{abstract}
As the title implies, a scientific paper reveals the issue of an optimal and effective form of modern education. It is emphasized that the methods of applying blended learning models in conditions of forced long-term isolation of students are studied. The positive and negative aspects of the education shift towards an interactive mode are identified, the principles of enhancing innovative educational process effectiveness are revealed.

It is stressed that blended learning is any learning process that involves the student gaining integrated learning experience, alternating classroom, and extracurricular activities. The latter is held in an electronic or online format, with partial or full teaching supervision. What is more, the teacher receives tools for innovative control of the educational activities of the class, as well as individual pupils and students. As a result, there is a gradual reorientation of the classical approach, when the class is focused on the teacher, and teaching is focused on a pupil or a student.

It is especially emphasized that the effectiveness of blended learning "closed" the issues of education at a difficult time for Ukraine, which was one of the reasons for the appearance of the Acts on education that allowed tutors to involve both our own and international educational online platforms in the educational process.
\end{abstract}

\footnotetext{
${ }^{1}$ Lecturer at the Department of Foreign Languages,

National Aerospace University «Kharkiv Aviation Institute», Ukraine

${ }^{2}$ Assistant Professor at the Department of Foreign Languages,

National Aerospace University «Kharkiv Aviation Institute», Ukraine
} 
It is specially noted that they, in turn, will ensure the continuity of the process of obtaining knowledge, lead to a modular type of study and even online certification.

However, it is reported that the forced introduction of blended learning has opened up a number of problems associated with the introduction of such training services.

It is worth noting that there is a lack of standards among the shortcomings of the emergency implementation of blended learning. In the paper, changes, as well as own copyright developments to adjust the common models of blended learning in order to minimize direct contacts between the teacher and students are proposed and justified. It should be stressed that the introduction of blended learning in modern educational process opens up wide horizons and unlimited possibilities for the teacher and student, which have yet to be studied and mastered by modern pedagogical science.

\section{1. Вступление}

Внедрение смешанного обучения в современный образовательный процесс, открывает широкие горизонты и неограниченные возможности перед преподавателем и учеником, которые еще предстоит изучить и освоить современной педагогической науке.

Процесс смешивания онлайн-обучения студента или школьника с изложением теории и практики, что называется «лицом к лицу» позволяет:

- разделить и индивидуализировать часть занятий в онлайнрежиме, оставив стандарты подачи материала на уроке или лекции;

- обеспечить необходимую помощь «по требованию» в процессе выполнения домашних заданий в режиме онлайн-поддержки с помощью существующих платформ или специально разработанных учебных приложений;

- создавать групповое изложение материала несколькими преподавателями;

- предложить ученику возможность выбора темпов обучения;

- реализовать групповые самостоятельные занятия, где онлайнрежим заменит «присутствие класса»;

- значительно расширить возможности образования и социального охвата для студентов и школьников с ограниченными возможностями. 
Долю онлайн-образования и традиционного изложения предмета можно определить в непрерывном процессе получения образования. На этапе начальной школы в первых классах дети полностью находятся под присмотром учителя, который обязан заложить:

- стандарты поведения и дисциплины;

- модели обучения, самообучения, наладить контроль выполнения заданий;

- развить социальные навыки коммуникации, личную ответственности привить основы самостоятельной работы, научить применять полученные знания.

К моменту перехода ученика младших классов в среднюю школу, он должен освоить начальные формы смешанного обучения. Учитель, в форме факультативных занятий, разбив класс на группы, прорабатывает с каждой из них модели выполнения заданий онлайн.

С каждым новым, групповым занятием, часть из них проходит без присутствия учителя. При этом группа детей должна собраться вместе, чтобы помочь друг-другу преодолеть возникшие проблемы в работе онлайн. По мере роста опыта учеников, можно переходить от группы к индивидуальным занятиям и тестам.

В средней и высшей школе доля онлайн-заданий начинает постепенно расти, преследуя цели:

- персонализации образования, развивая отдельные направления обучения в отдельных предметах и направлениях, по которым выявлены особые достижения ученика или студента;

- специализация образования - ученик или студент получает дополнительную специальность или образование;

- инновационная среда - различные экспериментальные образовательные проекты.

Появление онлайн-обучения в структуре средней и высшей школы, дает студентам и школьникам возможность перейти в будущем к образованию с отрытым кодом. Успешные модели факультативов и проектов можно оформить в одну социальную сеть. Преподаватели или студенты поделятся собственным опытом в виде приложений, развитию и обсуждении которых привлечет международное сообщество и различные профессиональные школьные или студенческие альянсы. 


\section{2. История смешанного обучения}

Модель классно-урочного образования, изложенная в XVII веке чешским писателем и педагогом Яном Амосом Коменским была изменена его не менее знаменитым коллегой Айзеком Питманом в следующем XVIII веке. Известный изобретатель авторской системы стенографии распространял свои знания по большей части дистанционно.

Это был первый метод смешанного образования, доказавший собственную эффективность при создании Питманом стенографического, фонетического института с филиалом в Нью-Йорке. Единые стандарты образования на двух континентах и подбор преподавателей осуществлялся методом писем и тестов.

Дистанционная системе Айзекс Питмана не прижилась, Ян Коменский был родоначальником научной педагогики и смешанным обучением не пользовались до 60-х годов XX века.

На данном историческом этапе появились первые компьютеры и возникла новая профессия программиста. Теоретические классные занятия при обучении кодеров, смешивались с дистанционной практикой написания программ.

Качество обучения в этом случае, контролировалось компиляторами - встроенные редакторы проверяли код и указывали на ошибки. Запуск написанного приложения свидетельствовал о выполненной работе, сложность задания служила оценкой уровня знаний программиста. Смешанное обучение идеально подходило для этого вида образования. Как результат - лучшая подготовка специалистов, транснациональность кадров, объясняющая сегодняшнее лидерство IT-компаний, обошедших по рекордам капитализации и прибыли предприятия любых, других отраслей.

Начиная с 1970-х годов, идею смешанного образования подхватила высшая школа. Стэнфордский Университет одним из первых записал и выпустил видеотрансляции лекций, практический занятий, по итогам которых любой желающий мог пройти обучения, выполнять задания и присылать письменные ответы на тесты.

Стэнфордская система смешанного образования получила международное распространение и используется по настоящее время для поиска талантливых студентов и подготовки абитуриентов. 
В 1990-е годы с развитием сети Интернет и началом массовой компьютеризации учебных заведений, педагоги из разных стран начали проводить научные и практические изыскания, ставить эксперименты с целью выработки методов совмещения двух типов образования.

Термин - смешанное обучение (Blended learning) принадлежит американским центрам интерактивного обучения в Атланте, выпустивших такое название в пресс-релизе 1999-го года, описывающим учебные услуги.

Первой моделью Blended learning стал «перевернутый класс», разработанный в 1998-м году учителями химии - Аароном Самсом и Джонатаном Бергманном.

Первые статьи этих авторов, опубликованные в 2000-м году, журналом университета штата Огайо считаются отправной точкой научного развития Blended learning, как отдельного научного направления.

С 2008-го года по настоящее время начато практическое международное внедрение смешанного обучения.

\section{3. Основные определения, методы, формы и практики современного смешанного обучения}

Смешанное обучение или blended learning получило полноценное развитие 10 лет тому назад. Гибридная форма подачи знаний в настоящий момент, находится в стадии формирования, поэтому имеет несколько основных определений.

Под смешанное обучение подпадает любой учебный процесс, предусматривающий получение учеником интегрированного опыта обучения, чередованием классных и внеклассных занятий. Последние проходят в электронном или онлайн-формате, с частичным или полным, преподавательским контролем.

При этом должно соблюдаться правило изложения части учебного плана в смешанном виде. Считается неверным, считать смешанным обучением, вынос в онлайн-режим только дополнительного, внеклассного образования.

Часть знаний при практике blended learning должна поступать только из интерактивных источников, т.е. школьная или программа высшего образования переформатируется в электронный формат. 


\section{1. Преимущества практик смешанного обучения для участников педагогического процесса}

Современный образовательный процесс переведенный на смешанное обучение, привить ученикам практики освоения способов организации интерактивной и самообразовательной деятельности, расширяющих образовательные возможности.

Ознакомившись в процессе обучения с различными уже существующими международными ресурсами, студент или школьник может заинтересоваться другими курсами или предметами на этих платформах.

Педагог способен определить талантливых и способных учеников, развивая их навыки в процессе онлайн-занятий, заданиями индивидуальной сложности.

Встроенность тестирования и автоматических оценок знаний, поможет объективизации достижений каждого отдельного ученика. Это в свою очередь повысит веру ученика в образовательный процесс продемонстрирует ему возможность влиять на оценку повышением уровня знаний, разовьет тягу к самостоятельному обучению.

Учитель получит возможность наиболее точно определять проблемы в отдельных блоках знаний по предмету, что поможет вовремя устранять пробелы и проблемы ученикам, путем интенсивных, индивидуальных онлайн или офлайн-занятий.

Практики смешанного образования для преподавателей, помогают повысить квалификацию педагогического состава, что впоследствии сделает его подготовленным к инновациям, внедряемым на уровне государственной политики.

В свою очередь преподаватели получат новые инструменты автоматического или алгоритмического контроля знаний учащихся, способы индивидуальной или групповой коммуникации.

Педагоги и школа смогут выделить и обособленно обучать высокомотивированных и талантливых учеников, повысив в цело качество подачи знаний. Этот процесс в свою очередь заставить учителя стать конструктором кейсов градации сложности предмета в рамках общей, учебной программы.

В конечном счете практики смешанного обучения трансформирую образовательный процесс в плане: 
- экономии средств на повышении квалификации преподавателя, вынужденного «идти в ногу» с одаренными учениками;

- расширение контингента учеников за счет расширения линейки профилирования образования;

- решить проблему кадров, путем сотрудничества и внедрения внешних онлайн-ресурсов;

- оптимизировать учебное время.

\section{2. Формы и методы смешанного обучения}

Современное развитие технологий, позволяет выбрать любую из форм смешанного обучения, дополнив урочно-классную систему различными электронными курсами, практическим обучением с выездом на объекты производства, учебой по интерактивным учебникам (электронным книгам), симуляциями и проектами.

Перечисленные формы обучения, задействованы в устоявшихся пяти методах системы blended learning:

1. «Лицом к лицу» (Face-to- Driver) - доминирует урочно-классное обучение, вышеописанные формы используются, как дополнительное образование.

2. Ротация - разделение учебной программы на электронно-дистанционное и классное обучение с последующим чередованием этих частей.

Подразделяется на три подвида ротации:

- классная - ученики проходят уроки в режиме онлайн и офлайн по расписанию;

- лабораторная - онлайн обучение проходит в лабораториях, внутри школы или ВУЗа;

- перевернутый класс (Flipped Classroom) - электронная и онлайнформа преобладает над традиционно урочно-классной системой, учеба характеризуется высокой степенью свободы выбора места, времени и набора предметов.

3. Self-blend модель - обучение одновременно в нескольких университетах в режиме онлайн.

4. Гибкая flex модель - высокая доля обучения онлайн, личные встречи с преподавателем только в режиме офлайн поддержки или консультаций, класс разбит на малые группы для постоянной работы над различными проектами (метод проектов). 
5. Виртуальная модель ВУЗа - лекции и занятия ведутся в онлайн, но в режиме реального времени по расписанию. Студент самостоятельно принимает решение посещать лекции или обучаться на виртуальной платформа, присутствовать на занятиях или смотреть их в записи.

Все модели смешанного образования определяют три основные составляющие, которые задействованы в разной степени пропорциональности:

- личное взаимодействие преподавателя и ученика или студента;

- онлайн-обучение;

- самообразование;

Они изменили традиционную классную систему, модифицировав роль педагога в координатора учебного процесса для класса в целом, самообразовательных траекторий для группового или индивидуального обучения, модератора образовательного онлайн-контента.

Преподаватель получает инструменты инновационного контроля учебной деятельности класса, а также отдельных учеников и студентов. В результате происходит постепенная переориентация классического подхода, когда класс ориентирован на педагога, на обучение, ориентированного на ученика и студента. Т.е., если раньше школа и ВУЗ занимались обучением, то теперь они помогают учиться.

\section{4. Смешанное обучение - эффективная форма оптимизации украинского образования в современных реалиях}

Смешанное обучение позволяет развивать дистанционное образование. Это перспективное направление, эффективно осуществляет важную миссию на текущем этапе развития страны.

\section{1. Смешанное обучение в зоне АТО и оккупированной территории АРК}

Национальной педагогике удалось охватить учебным процессом детей из зоны АТО и оккупированной территории АРК.

Граждане Украины, что остались на вышеперечисленных территориях, получили возможность использовать смешанное обучение на основании разъяснительного Письма Министерства образования и науки МОН.

Приказ №1/9-535 от 14.10.2014 г, дает детям возможность обучаться онлайн в школах, где организована экстернатура. Родители и ученики, 
на сегодняшний день, могут выбирать один из двух видов смешанного школьного обучения:

- полноценное дистанционное образование, где присутствуют онлайн-уроки, общение по скайпу с учителями, групповые виртуальные занятия;

- домашнее обучение по выданным школой стандартам программ среднего образования $\mathrm{MOH}$;

В первом случае, школы часто дополняют виртуальные занятия, офлайн встречами в конце четверти или по любому гибкому графику, во втором - знания ученика оценивается по государственной итоговой аттестации ДПА в 4, 9 и11 классах. Они определяют дальнейший допуск к ВНО для поступления в высшие учебные заведения.

\section{2. Эффективность смешанного обучения высшего образования}

Развитие дистанционной формы обучения в высших учебных заведениях, открывает возможности для абитуриентов выбирать более престижные ВУЗы или существенно экономить на платных, образовательных услугах.

Последнее - немаловажный социальный фактор для Украины. Смешанное обучение на этапе высшего профессионального образования, эффективно повышает качество, одновременно снижая стоимость образования.

Обучаясь в национальных ВУЗах студенты, параллельно с лекциями украинских преподавателей, знакомятся с онлайн-материалами лучших университетов.

\section{3. Эффективность смешанного обучения в процессе организации непрерывного образования}

Применение формы смешанного обучения в системе непрерывного образования - это еще один фактор доказательства эффективности инновационной модели.

Скорость развития технологий, требует от современного специалиста, проходить обучение не только после получения средне-специального и высшего образования, но и в процессе непосредственной профессиональной деятельности без отрыва от работы.

Смешанное обучение, позволит получить новые знания или провести процесс повышения квалификации в стенах alma mater. Сейчас 
специалистам приходится прибегать к услугам обучающих центров или других университетов, по причине географической удаленности от выпускающего ВУЗа в связи с переездом к месту трудоустройства или иным обстоятельствам.

Разработка и внедрения онлайн-программ, специально для выпускников, знания и личности которых может дистанционно верифицировать выпускающий факультет или кафедра:

- обеспечит целостность непрерывного образования и ответственность за обучение, повышающее престиж ВУЗа;

- повысит качество обучения - выпускник - специалист будет повышать квалификацию в «знакомой», научной среде;

- снизит стоимость услуг, часть затрат можно будет переложить на предприятия, готовых платить за специалистов с дипломом определенного университета и обязательством постоянного обновления знаний;

- стимулирует ВУЗы на работу в направлении постоянной актуализации базы знаний, чтобы иметь возможность выполнять обязательства повышения квалификации специалистов и конкурировать с другими учебными заведениями.

\section{4. Смешанное обучение - эффективная форма}

\section{дошкольного и школьного дополнительного образования}

В текущий момент смешанное обучение, практически никак не регулируется законами образования Украины, что открывает родителям учеников возможность свободной реализации дополнительного образования ребенка.

Ученик обязан овладеть знаниями в рамках утвержденной школьной программы - остальное время можно потратить на обучение по индивидуальному плану, составленному совместно со школой, преподавателем в рамках авторских курсов или обратиться к уже существующим проектам открытого самообразования.

Смешанное обучение в интернете реализуют онлайн-платформы $\mathrm{TED}$, edX или Coursera, подходящие для старших классов. Учащимся начальной школы подойдут международные программы Code.org и Khan academy. Среди национальных перспективных курсов смешанного обучения, можно отметить: ВУМ, Прометеус или EdEra. 
Смешанное обучение по международным или национальным проектам, позволяет эффективно решить географическую недоступность репетиторов или недостаток факультативов в школе по необходимым предметам.

\section{5. Оптимизация современного образовательного процесса с помощью смешанного обучения}

В 2017-м году Верховная Рада коренным образом изменила Закон об образовании Украины, чтобы создать условия переход от конвейерного и шаблонного типа получения знания, к компетентностному способу

Перед средней школой и высшими учебными заведениями, поставлена задача обеспечить условия для выпуска всесторонне развитых учеников и студентов, предоставить возможности для полного интеллектуального и духовно-нравственного развития.

Кардинальные изменения законодательства не означают слом или мгновенное форматирование сложившейся образовательной программы. Преподаватели, школы и университеты обязаны решить поставленные задачи путем оптимизации формы современного образования.

Смешанное обучение (Blended learning) - фактически единственная возможность решить поставленные перед профессиональным сообществом педагогов Украины, задачи. В рамках принятого Верховной Радой законодательства, blended learning прописана в новых формах получения образования:

- неформальная форма - законная возможность создания кружков, тренингов, курсов повышения квалификации;

- информальная форма - официальное разрешение на самообразование;

- инклюзивная форма - создание доступной учебной среды для учащихся и студентов с особыми потребностями.

Преподаватели и школы обязаны обеспечить подготовку учеников к тестированию ДПО и ВНО в рамках средней школы. Закон не предусматривает каких-либо жестких рамок для определения способов подачи материала, он может идти в смешанных формах, по усмотрению учебного заведения.

Касательно дополнительного образования - информальной формы или полного образования в инклюзивное среде, оно полностью может 
быть оптимизировано смешанным обучением. Преподаватель, вместе с родителями, может решить способы и меру своего присутствия в онлайн и офлайн-режиме, способы контроля практических задач, разбор и подачу теоретического материала.

Высшие учебные заведения уже перешли на blended learning по причинам:

- необходимости внедрения технических средств в рамках соответствия запросам на специалистов от реального рынка труда;

- конкуренции высшего образования среди ВУЗов;

- новаторства и свободы в создании учебных планов.

\section{1. Преимущества оптимизации современного образования методами смешанного обучения}

Смешанное обучение дает возможность виртуализации учебного процесса, выводит образование в наднациональные рамки с помощью привлечения любых сторонних преподавателей или международных образовательных проектов или платформ.

Применение вышеперечисленных методов оптимизирует обучение, в рамках школы или ВУЗа при смешанном обучении, ученик, студент и преподаватель, получают преимущества:

- освоение знаний в удобном для каждого формате;

- создание промежуточных точек контроля знаний или получение оценки успеваемости учащихся в режиме онлайн;

- оптимизацию временных затрат преподавателей на учебный процесс с целью высвобождения времени на более глубокую аналитику, разработку или модернизацию программ смешанного обучения;

- перевод ряда стандартов учебно-классной системы в режим онлайн;

- расширение границ социального общения до международного уровня;

- развитие у учеников навыков самостоятельного обучения и оценки;

- обретение учениками побочных навыков освоения современных информационных технологий.

Сочетание очной формы общения преподавателя с классом с выполнением заданий онлайн, при наличии обратной связи в виде динамичной оценки работы, позволит оптимизировать работу педагога в личностно-ориентированном ключе. 
Правильно составленное приложение и современные средства связи позволят во время удаленных сеансов занятий, уделять время отдельным ученикам. Преподаватель заранее увидит причину отставания и может точечно подправить знания, объясняя отдельные моменты учебного материала, в освоении которых, судя по выполнению заданий, отстал ученик.

\section{6. Проблемы внедрения смешанного обучения и способы их решения}

Смешанное обучение - практически единственная, безальтернативная форма образовательного процесса.

Несмотря на очевидность эффективности методов и объективность пользы оптимизации современного образования с помощью blended learning, существует целый ряд проблем, связанных с внедрением технологии:

- отсутствие единой операционной или облачной среды управления онлайн-обучением;

- проблемы, связанные с финансированием разработки, создания и реализации учебного контента;

- недостатки подготовки профессиональных педагогических кадров к работе в онлайн-среде;

- различный уровень знаний и навыков учеников и студентов, работы с гаджетами, прикладными программами, используемых в смешанном обучении;

- дефицит или отсутствие технических средств у учеников и учебных заведений.

Несмотря на распространенность Интернет-технологий, они сравнительно недавно пришли в семьи, школы и ВУЗы, что обусловило дефицит навыков работы и техническое отставание имеющихся материалов.

Большинство учебников, интерактивных курсов создания на $\mathrm{CD}$-носителях для работы в автономном режиме. Как следствие студент не получает тех навыков, что могли дать семинары, лекции или онлайн-курсы с обратной связью с преподавателем.

Педагоги часто не могут дать техническую консультацию, если учащийся испытывает проблемы с установкой или запуском файлов. 
Предоставленные материалы иногда нельзя открыть на уроке из-за слабой оснащенности классов компьютерной техникой.

Отсутствие стандартов порождают частные разработки учебного материала, который нельзя передать в другую школу или ВУЗ, иногда материал ориентирован на определенного преподавателя, по причине технически отсталой программной реализации курса.

Множество вышеперечисленных проблем способна решить пошаговая централизация развития смешанного обучения со стороны Министерства образования Украины. Изменения могли бы коснуться уроков информатики, которые выравнивали бы и развивали специальную подготовку учеников с онлайн-уроками еще на этапе начальной школы.

Это бы гарантировало наличие необходимого минимума знаний по IT-технологиям при поступлении абитуриента в ВУЗ.

Повышения квалификации преподавателей легко добиться системой финансовых поощрительных мер, тарифицируя отдельно оплату проведения смешанных уроков. В этом случае можно было бы контролировать долю онлайн-тематики в смешанном образовании, поставив изначально минимальную планку и постепенно добиваясь ее повышения.

Смешанное обучение следует вводить поэтапно, используя существующие платформы, мессенджеры, соцсети, получившие массовое распространение. С ними не возникнет проблем, так как они прочно стали одной из форм коммуникаций современных школьников и студентов.

Преподаватель должен начать переводить часть занятий на общение в виде форумов и групп, сводить задания к обмену файлами и простейшему тестированию.

\section{1. Основные элементы системы смешанного обучения}

В процессе перевода учебно-классной системы образования на смешанную систему на первом этапе можно задействовать следующие элементы для перевода части материалов в интерактивную форму.

- оформление лекций в виде презентационных материалов и онлайн-курсов;

- семинары с элементами отработки навыков будущего онлайнобщения;

- верификацию, адаптацию и использование сторонних учебников в электронной форме с мультимедийными приложениями; 
- онлайн-лекции в виде чатов и групповых конференций;

- индивидуальные и групповые проекты, направленные на развитие у класса навыков работы с Интернетом и приложениями, которые впоследствии будут использованы в смешанном обучении;

- создание виртуального класса;

- создание аудио/видео-лекционного материала.

Педагог должен подготовить учащихся к онлайн-работе, наработать навыки и проверить адекватность восприятия материала в интерактивном режиме. Стартовые занятия в смешанном обучении должны делиться на три фазы:

1. Подготовительный этап - проверка работы приложений и систем, рассмотрение тезисов материала, который будет обсужден в онлайн-режиме.

2. Тестирование, закрепление и проверка уже освоенных знаний, обсуждение новых тем.

3. Итоги онлайн-занятий и работа по новому материалу, согласно намеченному при онлайн-обсуждении, плану.

\section{2. Способы повышения эффективности смешанного обучения}

Эффективное применение смешанного обучения невозможно без этапа разработки и издания учебно-методических материалов в электронном виде, а также различных инструментов онлайн-тестирования.

Преподаватель должен заранее предусмотреть возможность компьютерной поддержки учеников и студентов, формат программы, совместимый с гаджетами и компьютерами.

Интерактивная учебная программа должна быть ориентирована под распространенные приложения и иметь стандартные электронные форматы. Онлайн-обучение и виртуальные классы должны быть рассчитаны на минимально доступную скорость передачи данных, равную возможностям мобильных операторов и провайдеров.

Интерактивные курсы должны быть доступны для записи на диски или флэш-память, загрузки на сайты и ориентированы на прохождения материала в автономном режиме.

Смешанное обучение должно быть разнообразным и не заключаться только в трансляции видеокурсов. Подобная подача материала негативна тем, что ученики и студенты не имеют обратной связи с преподавателем. 
Основные принципы эффективности смешанного обучения:

- целенаправленность и подробный алгоритм перехода от одного типа подачи знаний к другому (ротация вышеописанных методов blended learning);

- системный подход к ученикам и студентам, готовящий к освоению технологий, интерактивного материала, смешиванию офлайн и онлайн-расписания;

- система тестирования и определения эффективности обучения в режиме онлайн;

- способы анализа потребности и меры смешанного обучения;

- разработка сценариев для индивидуального образования;

- документирование смешанного обучения с целью дальнейшего продвижения в МОН Украины для получения финансирования на организацию виртуальных классов и интерактивных материалов.

\section{7. Выводы}

В первых главах монографии, была кратко исследована история появления и развития смешанного обучения. Как видно, необходимость в нем появилась еще в XVIII веке, позволив быстро распространить специфические знания (стенографии и правописания) в международном формате, даже при отсутствии современных средств коммуникаций.

Они получили полноценное развитие в XX веке с появлением компьютеров и Интернета, с которыми неразрывно связано распространение смешанного образования. Оно эволюционировало вертикально, «сверху вниз», сначала затронув квалификационную подготовку технических специалистов, добравшись до высшей школы и теперь перешло на среднюю школу.

Эффективность blended learning «закрыла» вопросы образования в трудный час для Украины, что стало одной из причин появления статей в законе об образовании, разрешающих привлекать в учебный процесс, как собственные, так и международные образовательные онлайн-платформы.

Именно открытость учебного процесса в сети Интернет, обусловит дальнейшие перспективы развития смешанного образования. Важность гибкости процесса получения образования и качественности знаний, выведет blended learning на «открытый код». 
Успех развития международных проектов, может привести к созданию единой платформы образования с открытым доступом и возможностью скачивания различных приложений.

Они в свою очередь обеспечат непрерывность процесса получения знаний, приведут к модульному типу учебы и даже онлайн-аттестациям, где верификацию личности обеспечат id-идентификаторы, биометрия или электронные базы персональных данных государства.

Развивая внедрение смешанного обучения в современном образовании важно понимать, что blended learning при всей эффективности и оптимальности, никогда не вытеснит урочно-классную систему. Профессиональный педагог имеет ментальную связь с классом, что делает каждое занятие уникальным, при одном и том же «выдаваемом» объеме знаний.

Благодаря чувству общего настроя, эмоционального фона, преподаватель выбирает раз за разом, правильные методы и скорость изложения материала. Ни одной современной технологии, будет невозможно передать общее состояние и готовность группы удаленных студентов к приему знаний, лишив учителя возможности определять проблемные места и расставлять акценты в выдаваемой теории.

\section{Список литературы:}

1. Bonk C. J., Graham, C. R. Handbook of Blended Learning: Global Perspectives, Local Designs. San Francisco, CA : Pfeiffer Publishing, 2006.

2. Васин Е.К. Об оценке продуктивности смешанного обучения на основе функционирования деятельностного треугольника. Современные проблемы науки и образования. 2016. Вип. 2. С. 33-41.

3. Логинова А.В. Смешанное обучение: преимущества, ограничения и опасения. Молодой ученый. 2015. № 7. С. 809-811.

4. Локшина O.I. Теоретико-методологічні підходи до проблеми змісту шкільної освіти. Зміст шкільної освіти в країнах $Є С$ : теорія $і$ практика (друга половина $X X-$ початок XXI cm.) : монографія / O.I. Локшина. Київ : СПД Богданова А.М., 2009. С. 57-82.

5. Мясникова Т.С., Мясников С.А. Система дистанционного обучения Moodle. Харьков : Изд-во Шейниной Е.В., 2008. 232 с.

6. Нагаева И.А. Моделирование процесса преподавания в виртуальном, образовательном пространстве ВУЗа. Перспективы науки и образования. 2013. № 4. C. 79-92. URL: https://pnojournal.wordpress.com/archive/13-04/ (дата обращения: 01.12.2020).

7. Про затвердження Положення про дистанційне навчання : Наказ Міністерства освіти і науки України від 25 квітня 2013 року № 466/2013/ Міністр 
освіти і науки України. URL: https://zakon.rada.gov.ua/laws/show/z0703-13\#Text (дата обращения: 30.11.2020).

8. Щодо організації навчання у загальноосвітніх навчальних закладах осіб, що проживають на тимчасово окупованій території в Автономній Республіці Крим, місті Севастополі та у місцях проведення антитерористичної операції в Донецькій і Луганській областях : Лист МОН від 14 жовтня 2014 року №1/9 - 535/2014 / Департамент освіти і науки обласних державних адміністрацій Київської міської ради. URL: http://ru.osvita.ua/legislation/ Ser_osv/43287/ (дата обращения: 30.11.2020).

\section{References:}

1. Bonk C. J., Graham, C. R. (2006) [Handbook of Blended Learning: Global Perspectives, Local Designs]. San Francisco, CA: Pfeiffer Publishing.

2. Department of Education and Science of Regional State Administrations of Kyiv City Council (2014, October 14). Letter of the Ministry of Education and Science on the organization of training in secondary schools of persons living in the temporarily occupied territory in the Autonomous Republic of Crimea, the city of Sevastopol and in places of anti-terrorist operation in Donetsk and Luhansk regions, no. 1/9-535/2014. Available at: http://ru.osvita.ua/legislation/Ser_osv/43287/ (accessed 30 November 2020).

3. Loginova A.V. (2015) Smeshannoe obuchenie: preimushchestva, ogranicheniya i opaseniya [Blended learning: benefits, limitations and concerns]. Young scientist, no. 7, pp. 809-811.

4. Lokshyna O.I. (2009) Teoretyko-metodolohichni pidkhody do problemy zmistu shkilnoi osvity [Theoretical and methodological approaches to the problem of the content of school education]. Zmist shkilnoi osvity v krainakh YeS: teoriia i praktyka (druha polovyna XX - pochatok XX st.) [The content of school education in the EU: theory and practice (second half of XX - early XXI century.)]. Kyiv: SPD Bohdanova A.M., pp. 57-82.

5. Minister of Education and Science of Ukraine (2013, April 25). Order of the Ministry of Education and Science of Ukraine on approval of the Regulations on distance learning, no. 466/2013. Available at: https://zakon.rada.gov.ua/laws/show/ z0703-13\#Text (accessed 30 November 2020).

6. Myasnikova T.S., Myasnikov S.A. (2008) Sistema distantsionnogo obucheniya Moodle [Moodle distance learning system]. Khar'kov: Izd-vo Sheyninoy E.V. (in Russian)

7. Nagaeva I.A. (2013) Modelirovanie protsessa prepodavaniya v virtual'nom, obrazovatel'nom prostranstve VUZa [Modeling the teaching process in the virtual, educational space of the university]. Perspektivy nauki i obrazovaniya (electronic journal), no. 4, pp. 79-92. Available at: https://pnojournal.wordpress.com/ archive/13-04/ (accessed 01 December 2020).

8. Vasin Y.K. (2016) Ob otsenke produktivnosti smeshannogo obucheniya na osnove funktsionirovaniya deyatel'nostnogo treugol'nika [On the assessment of the productivity of blended learning based on the functioning of the activity triangle]. Modern problems of science and education, vol. 2, pp. 33-41. 